\title{
Hydraulic residence time and iron removal in a wetland receiving ferruginous mine water over a 4 year period from commissioning.
}

\begin{abstract}
Analysis of residence time distribution (RTD) has been conducted for the UK Coal Authority's mine water treatment wetland at Lambley, Northumberland, to determine the hydraulic performance of the wetland over a period of approximately 4 years since site commissioning. The wetland RTD was evaluated in accordance with moment analysis and modelled based on a tanks-in-series (TIS) model to yield the hydraulic characteristics of system performance. Greater hydraulic performance was seen during the second site monitoring after 21 months of site operation i.e. longer hydraulic residence time to reflect overall system hydraulic efficiency, compared to wetland performance during its early operation. Further monitoring of residence time during the third year of wetland operation indicated a slight reduction in hydraulic residence time, thus a lower system hydraulic efficiency. In contrast, performance during the fourth year of wetland operation exhibited an improved overall system hydraulic efficiency, suggesting the influence of reed growth over the lifetime of such systems on hydraulic performance. Interestingly, the same pattern was found for iron (which is the primary pollutant of concern in ferruginous mine waters) removal efficiency of the wetland system from the second to fourth year of wetland operation. This may therefore, reflect the maturity of reeds for maintaining efficient flow distribution across the wetland to retain a longer residence time and significant fractions of water involved to enhance the extent of treatment received for iron attenuation. Further monitoring will be conducted to establish whether such performance is maintained, or whether efficiency decreases over time due to accumulation of dead plant material within the wetland cells.
\end{abstract}

Keyword: Hydraulic residence time; Iron removal; Mine water; Wetland. 